\title{
Association of telomere length and telomerase methylation with n-3 fatty acids in preschool children with obesity
}

\author{
Xuanyi Liư ${ }^{\dagger}$ Xiaozhou Liư ${ }^{\dagger}$ Qiaoyu Shi, Xiuqin Fan and Kemin Qi ${ }^{*}$
}

\begin{abstract}
Background: Telomeres play a crucial role in cellular survival and its length is a predictor for onset of chronic noncommunicable diseases. Studies on association between telomeres and obesity in children have brought discrepant results and the underlying mechanisms and influential factors are to be elucidated. This study aimed to investigate changes in telomere length and telomerase reverse transcriptase (TERT) DNA methylation, and further to determine their correlation with n-3 polyunsaturated fatty acids (PUFAs) in preschool children with obesity.

Methods: Forty-six preschool children with obesity aged 3 to 4 years were included in the study, with equal numbers of age- and gender-matched children with normal weight as control. Leukocyte telomere length was determined by the ratio of telomeric product and single copy gene obtained using real-time qPCR. DNA methylation of TERT promoter was analyzed by bisulfite sequencing. Fatty acids in erythrocytes were measured by gas chromatography with a total of 15 fatty acids analyzed. The total saturated fatty acids (SFAs), total n-6 PUFAs, total n-3 PUFAs, and the ratio of arachidonic acid (AA) to docosahexaenoic acid (DHA) were calculated. Then the correlation between leukocyte telomere length, TERT promoter methylation and fatty acids was determined.
\end{abstract}

Results: In preschool children with obesity, leukocyte telomeres were shortened and had a negative association with the body mass index. The methylated fractions in 13 of $25 \mathrm{CpG}$ sites in the TERT promoter were increased by approximately 3 to 35\% in the children with obesity compared to the normal weight children. Erythrocyte lauric acid and total SFAs, lenoleic acid and total n-6 PUFAs were higher, and DHA was lower in the children with obesity than those in the children with normal weight. Correlative analysis showed that leukocyte telomere length had a positive association with total SFAs and DHA, and a negative association with the AA/DHA ratio. However, no association between erythrocyte DHA and the TERT promoter methylation was found.

Conclusion: These data indicate that the reduced body DHA content and increased AA/DHA ratio may be associated with shortened leukocyte telomeres in child obesity, which is probably not involved in the TERT promoter methylation.

Keywords: Child obesity, Leukocyte telomere length, Telomerase reverse transcriptase, DNA methylation, N-3 fatty acids

\footnotetext{
* Correspondence: qikemin@bch.com.cn

${ }^{+}$Xuanyi Liu and Xiaozhou Liu contributed equally to this work.

Laboratory of Nutrition and Development, Beijing Pediatric Research Institute,

Beijing Children's Hospital, Capital Medical University, National Center for

Children's Health, No.56 Nan-li-shi Road, Beijing 100045, China
}

(c) The Author(s). 2021 Open Access This article is licensed under a Creative Commons Attribution 4.0 International License, which permits use, sharing, adaptation, distribution and reproduction in any medium or format, as long as you give appropriate credit to the original author(s) and the source, provide a link to the Creative Commons licence, and indicate if changes were made. The images or other third party material in this article are included in the article's Creative Commons licence, unless indicated otherwise in a credit line to the material. If material is not included in the article's Creative Commons licence and your intended use is not permitted by statutory regulation or exceeds the permitted use, you will need to obtain permission directly from the copyright holder. To view a copy of this licence, visit http://creativecommons.org/licenses/by/4.0/. The Creative Commons Public Domain Dedication waiver (http://creativecommons.org/publicdomain/zero/1.0/) applies to the data made available in this article, unless otherwise stated in a credit line to the data. 


\section{Background}

The rapidly increased prevalence of childhood obesity and its associated comorbidities including obstructive sleep apnea syndrome, psychological problems, cardiovascular diseases, type 2 diabetes, cancers, etc., are seriously threatening short-term and long-term health [1]. The underlying mechanisms for the obesity associated complications are attributable to the chronic inflammation, formation of reactive oxygen species (ROS), lipid peroxidation, and resulted DNA instability or damage [2, 3]. Telomeres, specialized DNA-protein structures located at the ends of eukaryotic chromosomes, have been found to be negatively correlated to obesity in length, being with an important heterogeneity $[4,5]$. In children, studies have brought discrepant results, with some showing that obesity is related to shorter telomeres [6-8] but others finding no association $[9,10]$.

Telomeres are composed of repetitive DNA with highly conserved sequences ( $5^{\prime}$-TTAGGG-3'), and associated proteins [11], and play a crucial role in cellular survival, by maintaining chromosome stability and limiting progressive loss of genomic information caused by semi-conservative replication of DNA during the cycle of cell division [12, 13]. Telomere maintenance requires the active telomerase that is a ribonucleic acid-protein complex (RNP) composed of a single long non-coding telomerase RNA (TER), telomerase reverse transcriptase (TERT), and other proteins that vary among organisms, and functions to add telomeric repeat DNA to chromosome ends $[14,15]$. It has been demonstrated that telomerase activity is mostly undetectable in somatic cells several weeks after birth, and high in cells with high generative potentials, such as germ line cells, hematopoietic and few types of stem cells, most cancer cells, and during embryonic development [16-18]. Mutations in many of the core telomerase RNP subunits, promoter elements, as well as the maturation factors lead to telomerase deficiency diseases such as dyskeratosis congenita or aplastic anemia, while its aberrant upregulation is a prerequisite for the immortal phenotype of most cancer cells [19-22]. In cancers, DNA hypermethylation with the TERT promoter is a prevalent telomerase-activating mechanism that can act independently of or in conjunction with promoter mutations $[19,20]$.

Cumulative evidences show that telomere length can be affected by many factors, such as age, gender, genetic variation, physiological stress, lifestyle factors (smoking, obesity, and lack of exercise), environmental exposure to carcinogens, and diseases (cancer, etc.) [14, 23]. Most of the telomere loss happens in the first 4 years of age, plateauing by age 4 , with the greatest amount of attrition within the first years of life [18], followed by a slower attrition rate throughout adulthood. In obesity, telomere length is negatively associated with body weight and fat mass in American Indians, independently of chronological age, lifestyle factors and obesity-related inflammation or comorbidities [4]. Regarding the effects of diet and nutrients, most studies indicate that a healthy diet characterized by a high intake of dietary fiber and unsaturated lipids exerts a protective role on telomere health, whereas high consumption of sugar and saturated lipids accelerates telomere attrition [24]. National Health and Nutrition Examination Survey indicated that higher mineral and vitamin consumption is associated with longer telomeres among adults in the United States [25]. Vitamin D supplementation is found to be able to increase peripheral lymphocyte telomerase activity in overweight African Americans [26].

Since the 1960's, indiscriminate recommendations have been made to substitute vegetable oils (high in $n-6$ PUFAs and low in n-3 PUFAs) for saturated fats, resulting in the increased ratio of $n-6 / n-3$ PUFAs. This dietary fat change has been considered to be related to the increased prevalence of chronic non-communicable diseases including obesity, diabetes, cardiovascular diseases in modern society [27]. Under intake of n-3 PUFAs and its imbalanced ratio to $n-6$ PUFAs in early life may be an important determinant for adipocyte differentiation and growth and may relate to obesity pathogenesis in later life $[28,29]$. Proposed mechanisms by which $n-3$ PUFAs improve body composition and counteract obesity-related metabolic changes include modulating lipid metabolism, adipokine expression and adipogenesis, alleviating adipose tissue inflammation and oxidative stress, and altering epigenetics [29-32]. Therefore, this study aimed to investigate changes in telomere length and TERT promoter DNA methylation, and further to determine their correlation with n-3 PUFAs in preschool children with obesity.

\section{Methods \\ Subjects}

A total of 50 preschool children with obesity aged 3 to 4 years and equal numbers of age- and gender-matched lean (normal weight) children were recruited in the study, during the yearly routine health examination in residential community in Beijing. After reviewing the documents and 4 children in each group excluded due to failure in blood sample drawn, 46 obese children and equal numbers of matched lean normal children were included in a final study. The detailed information was recorded on children's height and body weight, feeding after birth, maternal age at birth, maternal education marital status, etc. Obesity was defined as having a body mass index (BMI) in the $\geq 2 \mathrm{SD}$ based on the WHO Multicentre Growth Reference Chart [33]. Children who had metabolic, endocrine and hereditary disorders, and 
diseases treated with glucocorticoids were excluded. Heparin-anticoagulant peripheral blood samples were collected. After centrifugal separation, the plasma was used for biochemical parameters of health examination, and the blood cells were stored at $-80^{\circ} \mathrm{C}$ for determination of telomere length and TERT DNA methylation. The Institutional Review Board and Committee on $\mathrm{Hu}$ man Research at Beijing Children's Hospital approved the study (No. 2016-3). The mothers or other legal guardians gave written consent for their participation and their children's participation.

\section{Determination of telomere length}

Determination of telomere length was ascertained using the real-time qPCR on a CFX96 Touch TM Real-Time PCR Detection System (Bio-Rad), based on extracted genomic DNA from the peripheral leukocytes. Telomere length was measured by the ratio of telomeric DNA product to single copy gene ( $\mathrm{T} / \mathrm{S}$ ratio), which was calculated by $2^{-(\Delta \mathrm{C} t \mathrm{t}-\Delta \mathrm{C} \mathrm{t} \text { s) }} /$ mean of all plates $2^{-(\Delta \mathrm{C} \mathrm{t} \mathrm{t}-\Delta \mathrm{C}}$ ${ }^{\mathrm{t} s)}=2^{-\Delta \Delta \mathrm{C} t} /$ mean $2^{-\Delta \Delta \mathrm{C} t}[34]$. The primers for the telomere PCR were tel. 1: 5' -GGTTTTTGAGGGTGAGGG TGAGGGTGAGGGTGAGGGT-3', and tel. 2: 5' TCCCGACTATCCCTATCCCTATCCCTATCCCTAT CCCTA-3', and the primers for the single copy gene human $\beta$-globin were Hbg1: 5'-GCTTCTGACACAACTG TGTTCACTAGC-3', Hbg2: 5'-CACCAACTTCATCC ACGTTCACC-3'. Each reaction was performed in the final volume of $20 \mu \mathrm{l}$. The thermocycle program consists of an initial hot start cycle at $95^{\circ} \mathrm{C}$ for 30 s, followed by 40 cycles at $95^{\circ} \mathrm{C}$ for $5 \mathrm{~s}, 60^{\circ} \mathrm{C}$ for $15 \mathrm{~s}$ and $72{ }^{\circ} \mathrm{C}$ for $10 \mathrm{~s}$.

\section{Bisulfite conversion and sequencing}

The examined TERT promoter region includes nucleotides (nts) 1,254,147-1,253,148 and spans 25 CpGs within nts -746 to -445 [positions are given relative to the transcription start site] (Fig. 1). The obtained sequence data have been submitted to the GenBank database (http://www.ncbi.nlm.nih.gov) under accession NC_000005, and contain binding sites for myeloidspecific zinc finger protein 2 (MZF2). DNA methylation of the promoter was analyzed by bisulfite sequencing. Genomic DNA was isolated and purified from the peripheral leukocytes in children with obesity and normal weight ( $n=46$ each), using a TIANamp Micro DNA Kit (Tiangen Biotech, Beijing, China), and then was quantified and quality assessed by nanodrop ND-1000. Genomic DNA bisulfate conversion was conducted using the EZ DNA MethylationTM Kit (Cat. No. D5001, ZYMO Research, USA). The methyl-modified DNA was amplified by nested PCR and the products were sequenced directly. Specific primers for the TERT promoter were as follows: F, 5' - TTTGAGAATTTGTAAA GAGAAATGA-3'; inner R, 5' - AATATAAAAA CCCTAAAAACAAATAC-3'; outer R, 5' - AAAAAA ACCATAATATAAAAACCCT-3'. DNA methylation was calculated from the amplitude of cytosine and thymine within each $\mathrm{CpG}$ dinucleotide, $\mathrm{C} /(\mathrm{C}+\mathrm{T})$, as described by Lewin et al. [35].

\section{Analysis of fatty acid profiles in erythrocytes}

Fatty acids in erythrocytes were measured by gas chromatography $(\mathrm{GC})$ in children with obesity and normal weight ( $n=20$ each) included for examination of the TERT promoter methylation. Fatty acid methyl esters (FAMEs) from red blood cells were prepared according to a modified method of Lepage [36, 37]. Briefly, $200 \mu \mathrm{l}$ of erythrocytes was added to $2 \mathrm{ml}$ of a mixture solution of methanol $n$-hexane $(4: 1, \mathrm{vol} / \mathrm{vol})$ containing C15:0 (an internal standard) and $2 \mu \mathrm{l}$ of BHT $(20 \mathrm{mM})$ to prevent lipid oxidation, and then $0.2 \mathrm{ml}$ of acetyl chloride was slowly added. After heating at $100^{\circ} \mathrm{C}$ for $1 \mathrm{~h}, 5 \mathrm{ml}$ of a $6 \% \mathrm{~K} 2 \mathrm{CO} 3$ solution was added to the tube, mixed on a vortex and centrifuged, and the clear n-hexane top layer containing FAMEs was transferred to a GC autosampler

\section{(-746)ctgagaactgcaaagagaaatgacgggcetgtgtcaaggagccaagt cgcgggga agtgttgcagggaggcactcegga}

MZF-2

ggtccegcgtgccegtccagggagcaatgcgtcetcgggttcgttcccagc cgcgtctacgegcetccgtcetccecttcacgtccggcattcgt
234
56
7 MZF-2 89
1011
12 MZF-2 1314
15

ggtgcccggagccegacgeccegegtccggacctggaggcagectgggtctccggatcaggecagcggccaaagggtcgecgcacgeac
16

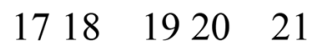
22
$2324 \quad 25$

\section{ctgttcceagggectccacatcatggecctcc $(-445)$}

Fig. 1 Primer sequences of the TERT promoter. The examined TERT promoter region includes nucleotides (nts) 1,254,147-1,253,148 and spans 25 CpGs within nts -746 to -445 (positions are given relative to the transcription start site), containing 3 binding sites (boxed) for myeloid-specific zinc finger protein 2 (MZF2). CpG sites are labeled with shadow and numbered from 1 to 25 . Primers were shown in bold and the primer outer $\mathrm{R}$ was underlined 
Table 1 Clinical characteristics and leukocyte telomere length in children with obesity versus normal weight

\begin{tabular}{llll}
\hline & $\begin{array}{l}\text { Obese }(\boldsymbol{n = 4 6 )} \\
(\mathbf{F}=\mathbf{2 0}, \mathbf{M = 2 6})\end{array}$ & $\begin{array}{l}\text { Control }(\boldsymbol{n}=\mathbf{4 6}) \\
(\mathbf{F = 2 1} \mathbf{M = 2 5})\end{array}$ & $\mathbf{P}$ \\
\hline Age (years) & $3.31 \pm 0.47$ & $3.25 \pm 0.66$ & 0.5884 \\
BMI $\left(\mathrm{kg} / \mathrm{m}^{2}\right)$ & $19.52 \pm 1.71^{\mathrm{a}}$ & $15.05 \pm 0.80$ & $<0.0001$ \\
BMI SDS & $2.93 \pm 1.23^{\mathrm{a}}$ & $-0.41 \pm 0.59$ & 0.0001 \\
Weight at birth $(\mathrm{g})$ & $3527.19 \pm 422.21^{\mathrm{a}}$ & $3287.81 \pm 448.19$ & 0.0084 \\
Length at birth $(\mathrm{cm})$ & $50.33 \pm 1.54$ & $49.87 \pm 1.51$ & 0.1497 \\
BMI at birth $\left(\mathrm{kg} / \mathrm{m}^{2}\right)$ & $13.92 \pm 1.26^{\mathrm{a}}$ & $13.46 \pm 2.16$ & 0.0069 \\
Gestational age at delivery (wk) & $38.98 \pm 1.47$ & $38.75 \pm 1.48$ & 0.4514 \\
Breast feeding within 3 months & $19 / 40^{\mathrm{a}}$ & $31 / 42$ & 0.0162 \\
Breast feeding within 6 months & $13 / 37$ & $22 / 40$ & 0.0803 \\
Leukocyte telomere length (T/S) & $0.88 \pm 0.36^{\mathrm{a}}$ & $1.05 \pm 0.39$ & 0.0433 \\
\hline
\end{tabular}

${ }^{\mathrm{a} S i g n i f i c a n t}$ differences between the obese and control children

vial for analysis. FAMEs were analyzed according to our previously described method on an Agilent 6890 N GC system, and the quantity of fatty acids was expressed as the percent (\%) (wt/wt) of the total fatty acids [38].

\section{Statistical analysis}

Based on the estimated sample size (from 19 to 192) with $\alpha=0.05$ and $\beta=0.1$, and changes in telomere length with obesity published, a total of 50 obese children and equal numbers of age- and gender-matched children with normal weight were recruited in the study. Analyses were performed using the GraphPad Prism 8.0. The Lilliefors test was used to evaluate whether the data is normally distributed, where $P>0.05$ indicates normally distribution. Two-tailed t-test was used for the normally distributed data and two-sided Wilcoxon rank-sum test was used for the non-normally distributed data to analyze the differences between two groups. The Pearson correlation was used to determine the correlations between two parameters. All data were expressed as means $\pm \mathrm{SD}$, and $P<0.05$ was considered to be statistically significant.

\section{Results}

Changes in telomere length in children with obesity

The characteristics of subjects in this study were presented in Table 1. As expected, the leukocyte telomere
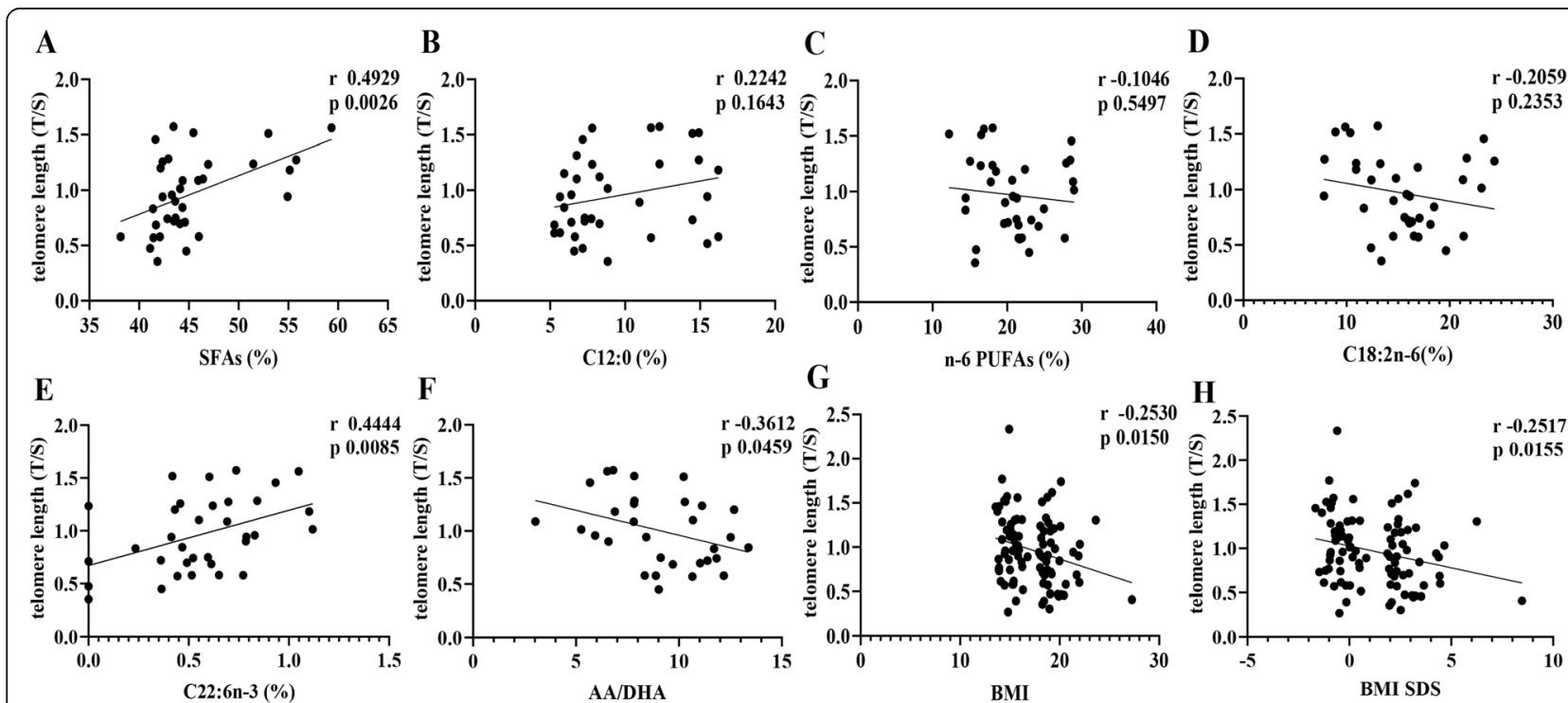

F

G
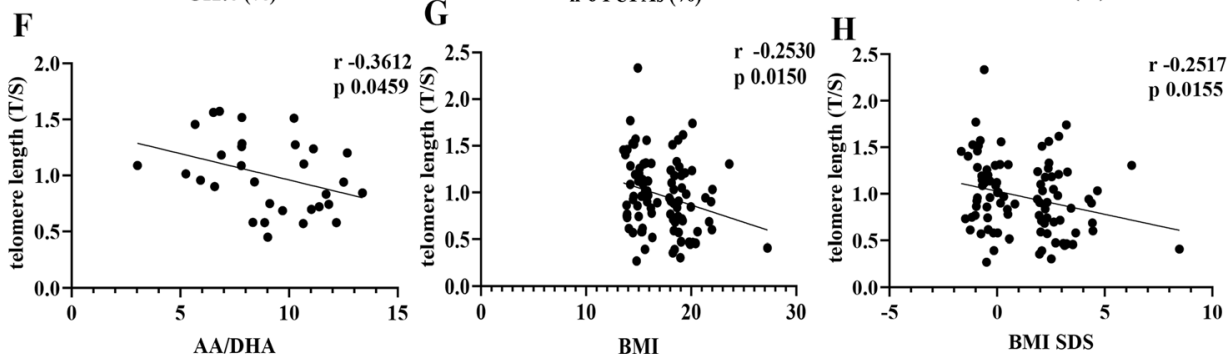

Fig. 2 Associations of telomere length with erythrocyte fatty acid compositions and BMI. Leukocyte telomere length in children with obesity and normal weight ( $n=46$ each) was determined using the real-time $\mathrm{qPCR}$, and expressed as the ratio of telomeric product and single copy gene obtained. Meanwhile, fatty acids in erythrocytes ( $n=20$ each group) were measured by gas chromatography, and their quantity was expressed as the percent (\%) of the total fatty acids. The associations of telomere length with fatty acids, BMI and BMI SDS were analyzed by the

Pearson correlation 
length was reduced in children with obesity compared to children with normal weight $(P<0.05)$. Correlative analysis showed a negative association between telomere length and the BMI as well as BMI SDS $(P<0.05)$ (Fig. 2). Additionally, children with obesity had higher birth weight and birth BMI and lower breastfeeding rates within the first 3 months postnatally $(P<0.05)$. No correlation between age as months and telomere length was indicated (Additional file 1).

\section{Changes in DNA methylation of the TERT promoter in children with obesity}

As shown in Table 2, a total of 25 CpG sites at the TERT promotor were determined for DNA methylation. The methylated fractions in $13 \mathrm{CpG}$ sites were significantly increased by approximately 3 to $35 \%$ in children with obesity compared with children with normal weight $(P<0.05)$, including $7 \mathrm{CpG}$ sites located at areas for binding MZF2. Correspondently, the averaged

Table 2 Changes in methylation fraction of CpG sites of the TERT promoter in children with obesity

\begin{tabular}{|c|c|c|c|c|}
\hline CpG sites & Obese $(n=46)$ & Control $(n=46)$ & $\mathrm{t}$ & $P$ \\
\hline 1 & $0.71 \pm 0.05$ & $0.70 \pm 0.03$ & 0.773 & 0.4414 \\
\hline 2 & $0.72 \pm 0.05$ & $0.71 \pm 0.03$ & 1.864 & 0.0653 \\
\hline 3 & $0.46 \pm 0.08$ & $0.45 \pm 0.03$ & 1.152 & 0.2523 \\
\hline 4 & $0.72 \pm 0.06^{\mathrm{a}}$ & $0.70 \pm 0.03$ & 2.434 & 0.0168 \\
\hline 5 & $0.60 \pm 0.07$ & $0.59 \pm 0.04$ & 0.696 & 0.4878 \\
\hline 6 & $0.33 \pm 0.06$ & $0.32 \pm 0.05$ & 1.034 & 0.3038 \\
\hline 7 & $0.50 \pm 0.05$ & $0.49 \pm 0.04$ & 1.747 & 0.0838 \\
\hline 8 & $0.55 \pm 0.06$ & $0.54 \pm 0.04$ & 1.757 & 0.0822 \\
\hline 9 & $0.54 \pm 0.08^{a}$ & $0.51 \pm 0.04$ & 2.207 & 0.0454 \\
\hline 10 & $0.63 \pm 0.06^{a}$ & $0.60 \pm 0.03$ & 2.745 & 0.0072 \\
\hline 11 & $0.58 \pm 0.08^{a}$ & $0.55 \pm 0.04$ & 2.434 & 0.0168 \\
\hline 12 & $0.66 \pm 0.05^{a}$ & $0.64 \pm 0.04$ & 2.023 & 0.0458 \\
\hline 13 & $0.27 \pm 0.08$ & $0.26 \pm 0.04$ & 1.010 & 0.3151 \\
\hline 14 & $0.56 \pm 0.08^{a}$ & $0.52 \pm 0.04$ & 3.030 & 0.0310 \\
\hline 15 & $0.38 \pm 0.07^{a}$ & $0.35 \pm 0.04$ & 2.375 & 0.0196 \\
\hline 16 & $0.41 \pm 0.09^{\mathrm{a}}$ & $0.38 \pm 0.04$ & 2.241 & 0.0270 \\
\hline 17 & $0.31 \pm 0.09^{a}$ & $0.27 \pm 0.04$ & 2.701 & 0.0082 \\
\hline 18 & $0.34 \pm 0.10$ & $0.31 \pm 0.04$ & 1.956 & 0.0533 \\
\hline 19 & $0.47 \pm 0.10^{a}$ & $0.43 \pm 0.05$ & 2.869 & 0.0051 \\
\hline 20 & $0.39 \pm 0.12^{a}$ & $0.33 \pm 0.04$ & 2.946 & 0.0041 \\
\hline 21 & $0.40 \pm 0.09$ & $0.37 \pm 0.04$ & 1.955 & 0.0535 \\
\hline 22 & $0.21 \pm 0.09^{\mathrm{a}}$ & $0.18 \pm 0.03$ & 2.894 & 0.0048 \\
\hline 23 & $0.23 \pm 0.14^{\mathrm{a}}$ & $0.17 \pm 0.06$ & 2.929 & 0.0044 \\
\hline 24 & $0.36 \pm 0.12$ & $0.33 \pm 0.06$ & 1.071 & 0.2872 \\
\hline 25 & $0.19 \pm 0.11$ & $0.16 \pm 0.06$ & 1.473 & 0.1447 \\
\hline Average & $0.47 \pm 0.06^{a}$ & $0.44 \pm 0.03$ & 0.405 & 0.0010 \\
\hline
\end{tabular}

${ }^{\mathrm{a}}$ Significant differences between the obese and control children methylation fraction was increased in children with obesity compared to children with normal weight $(P<$ 0.05). No association of $\mathrm{CpG}$ methylation fractions with telomere length was found (Additional file 1).

\section{Differences in erythrocyte fatty acids between children with obesity and normal weight}

The erythrocyte fatty acid compositions in two groups of children were presented in Table 3. Lauric acid (C12:0) and total saturated fatty acids, lenoleic acid (C18:2n-6) and total n-6 PUFAs were higher in children with obesity than those in children with normal weight $(P<0.05)$. Whereas, docosahexaenoic acid (DHA, C22:6n-3) was decreased in children with obesity, resulting in an increased ratio of arachidonic acid (AA, C20:4n-6) to DHA, compared to children with normal weight $(P<0.05)$.

\section{Correlative analysis between telomere length, TERT promoter methylation and erythrocyte fatty acids}

As shown in Fig. 2, the leukocyte telomere length was positively associated with concentrations of total SFAs and DHA in erythrocytes $(P<0.05)$, and negatively with the AA/DHA ratio $(P<0.05)$. However, no correlations between the TERT promoter methylation and erythrocyte fatty acid concentrations were indicated (Additional file 1).

\section{Discussion}

A systematic review and meta-analysis has demonstrated a negative correlation between adult obesity and telomere length with weak to moderate statistical significance for the main research, and an important heterogeneity [5]. In child population, studies investigating telomere length and obesity, and their causal relationship proved inconclusive [6-10]. In this study, in Chinese preschool children with obesity, leukocyte telomeres were shown being shortened and had a negative association with the BMI. This may increase the risk of metabolic complications in later life, because leukocyte telomere length has been found to predict onset of cardiometabolic diseases in adults, specifically diabetes mellitus and cardiovascular disease [39-41]. Also, the shorter telomere length in preschool age is associated with obesity at age 9 in Latino Children [9].

Although the molecular mechanisms by which obesity affects telomere length have not been described clearly, current research findings suggest that the shortened telomere was probably caused by the increased chronic inflammation and oxidative stress in obesity [42]. It is reported that expression of TERT, the key enzyme for maintaining telomere length, induced by cytokines is organized through the PI3K/AKT and NF/kB signaling pathways [22]. In the present study, we found that DNA methylation fractions of the TERT promoter were 
Table $\mathbf{3}$ Changes in erythrocyte fatty acids in children with obesity

\begin{tabular}{|c|c|c|c|c|}
\hline Variables & Obese $(n=20)$ & Control $(n=20)$ & $t$ & $P$ \\
\hline Total SFAs & $46.99 \pm 5.70^{\mathrm{a}}$ & $42.62 \pm 2.40$ & 3.1570 & 0.0031 \\
\hline C8:0 & $3.81 \pm 2.61$ & $3.23 \pm 1.76$ & 0.8174 & 0.4188 \\
\hline C10:0 & $0.18 \pm 0.16$ & $0.37 \pm 0.32$ & 2.2308 & 0.0265 \\
\hline C12:0 & $9.33 \pm 3.60^{a}$ & $4.92 \pm 0.92$ & 5.3060 & $<0.0001$ \\
\hline C14:0 & $0.04 \pm 0.09$ & $0.01 \pm 0.02$ & 1.6880 & 0.0994 \\
\hline C16:0 & $23.26 \pm 1.62$ & $24.00 \pm 2.22$ & 1.1960 & 0.2393 \\
\hline C18:0 & $10.36 \pm 1.67$ & $10.09 \pm 1.19$ & 0.5833 & 0.5631 \\
\hline Total MUFAs & $25.68 \pm 3.21$ & $25.36 \pm 2.78$ & 0.5562 & 0.5808 \\
\hline C16:1 & $0.95 \pm 0.50$ & $1.09 \pm 0.29$ & 0.3322 & 0.7416 \\
\hline C18:1 & $24.74 \pm 3.21$ & $24.27 \pm 2.70$ & 0.4996 & 0.6203 \\
\hline Total n-6 PUFAs & $19.40 \pm 3.85^{\mathrm{a}}$ & $22.46 \pm 5.29$ & 2.0930 & 0.0432 \\
\hline$C 18: 2 n-6$ & $14.09 \pm 3.91^{\mathrm{a}}$ & $17.11 \pm 4.55$ & 2.2490 & 0.0304 \\
\hline$C 20: 4 n-6$ & $5.28 \pm 1.61$ & $5.31 \pm 1.23$ & 0.0736 & 0.9417 \\
\hline$C 22: 5 n-6$ & $0.04 \pm 0.07$ & $0.05 \pm 0.09$ & 0.4042 & 0.6883 \\
\hline Total n-3 PUFAs & $7.92 \pm 2.64$ & $9.44 \pm 4.61$ & 1.3700 & 0.1787 \\
\hline$C 18: 3 n-3$ & $0.03 \pm 0.07$ & $0.00 \pm 0.00$ & 2.1580 & 0.0373 \\
\hline$C 20: 5 n-3$ & $3.77 \pm 1.59$ & $3.59 \pm 1.74$ & 0.3386 & 0.7368 \\
\hline$C 20: 4 n-3$ & $3.66 \pm 1.87$ & $5.16 \pm 3.13$ & 1.8380 & 0.0739 \\
\hline$C 22: 6 n-3$ & $0.46 \pm 0.33^{\mathrm{a}}$ & $0.80 \pm 0.46$ & 2.6650 & 0.0112 \\
\hline AA/DHA & $10.35 \pm 1.97^{\mathrm{a}}$ & $7.68 \pm 2.46$ & 3.4400 & 0.0016 \\
\hline Total n-6/n-3 PUFAs & $2.69 \pm 0.93$ & $3.17 \pm 2.08$ & 0.9510 & 0.3476 \\
\hline
\end{tabular}

${ }^{\mathrm{a}}$ Significant differences between the obese and control children

increased in children with obesity. Epigenetic changes including DNA methylation have been recognized to be the key players in governing gene expression, and higher promoter DNA methylation may down-regulate gene expression [43, 44]. The data presented here suggested that DNA hypermethylation at the TERT promoter might reduce mRNA expression of TERT and its activity, and thus lead to telomere attrition in obesity. Consistently, hypermethylation of the TERT promoter alleles signals transcriptional repression of those alleles, leading to attenuation of TERT activation in cancer cells [45]. In contrast, many studies reported that DNA hypermethylation of the TERT promoter is positively related to telomerase activity in cancers [20,46, 47].

The available evidence suggests that some antioxidant nutrients, the consumption of fruits and vegetables, and Mediterranean diet are mainly associated with longer telomeres [48]. With regard to macronutrients and telomeres, total protein and carbohydrates have not been clearly associated with telomere length; whereas the quality of carbohydrates, and particularly dietary fiber, may have a potential beneficial effect on telomere health $[49,50]$. The effects of dietary fats on telomeres have been studied in more detail than the other macronutrients. Although the overall relation of monounsaturated fatty acids and PUFAs with telomere length is inconsistent [48], most studies have demonstrated a positive relation between n-3 PUFAs and telomere length in adult chronic diseases [51-53]. Differently, a study on Chinese adults reported that n-6 PUFAs are positively, but n-3 PUFAs are negatively associated with leukocyte telomere [54]. Herein we found that erythrocyte DHA content was decreased in obese children, and had a positive association to leukocyte telomere length. Unfortunately, no association between erythrocyte DHA and DNA methylation of the TERT promoter was shown, although DHA functions to regulate DNA and histone methylation through affecting methyl group metabolism [31, 32, 55]. Therefore, the mechanisms by which DHA affects telomere length may reside in its anti-inflammatory or anti-oxidative stress effects $[29,30]$, but is independent of its function in epigenetic modification.

With respect to saturated fat, it has been reported that women with SFAs intake in the lowest compared to highest quartile had significantly longer telomeres, and that in men, high total fat, SFAs, and butter intake was inversely associated with telomere length [56, 57]. In contrast, we found that erythrocyte total SFAs were increased in children with obesity, and were positively correlated with telomere length. The underlying reasons 
could not be answered herein. It may be involved in more total fat and SFAs required for infants and toddlers than older children and adults. High fat diets are important during early life because of very high energy needed for growth and for the rapid development of the nervous system, and fat restrictions may affect body composition and increase obesity risk in later life [58]. To note, in addition to fatty acids, many other factors reported can affect telomere length, such as age, gender, physiological and psychological stress, sedentary lifestyle, exposure to environmental carcinogens, etc. [14, 23]. Thus, more researches are needed to clarify the underlying mechanisms for shortened telomere length in the future.

The duration of obesity could have a significant influence on the observed changes in telomeres. Unfortunately, the data after birth at fixed time points, reflecting the development of obesity, were not available and thus its effects on telomere length could not be investigated in the current study. This question should be highlighted as a future research perspective. Meanwhile, the severity of obesity may also affect telomeres. It could be intriguing to divide the children into moderate obese and severe obese, but the smaller number could not allow further analysis and satisfactions. Future studies with a large sample size may be helpful for this hypothesis test.

\section{Conclusion}

In summary, preschool children with obesity had shorter leukocyte telomeres, accompanied by DNA hypermethylation at the TERT promoter. A possible relationship between the shortened leukocyte telomeres and reduced body DHA content and increased AA/DHA ratio in obesity is suggested. However, the association of DHA with telomere length might not be involved in its modification on the TERT promoter DNA methylation.

\section{Supplementary Information}

The online version contains supplementary material available at https://doi. org/10.1186/s12887-020-02487-x

Additional file 1.

\section{Abbreviations}

AA: Arachidonic acid; BMI: Body mass index; DHA: Docosahexaenoic acid; FAMEs: Fatty acid methyl esters; MZF2: Myeloid-specific zinc finger protein 2; PUFAs: Polyunsaturated fatty acids; SFAs: Saturated fatty acids; TERT: Telomerase reverse transcriptase

\section{Acknowledgements}

Not applicable.

\section{Authors' contributions}

$X Y L$ performed the experiment, analyzed fatty acids and prepared the manuscript. XZL collected samples and analyzed leukocyte telomere length and DNA methylation. QS performed the experiment. XF designed the research and analyzed leukocyte telomere length. KQ designed the research and revised the manuscript. All authors read and approved the final manuscript.

\section{Funding}

This work was supported by the Research Funds of Profession Quota Budget from Beijing Municipal Science and Technology Commission (2020-bjsekyjs to K.Q.). The funders had no role in study design, data collection, and analysis, interpretation of data, decision to publish, or preparation of the manuscript.

\section{Availability of data and materials}

The datasets used and/or analysed during the current study are available from the corresponding author on reasonable request.

\section{Ethics approval and consent to participate}

The Institutional Review Board and Committee on Human Research at Beijing Children's Hospital approved the study (No. 2016-3). The mothers gave written consent for their participation and their children's participation.

Consent for publication

Not applicable.

\section{Competing interests}

The authors declare that they have no competing interests.

Received: 18 August 2020 Accepted: 22 December 2020

Published online: 07 January 2021

References

1. World Health Organization. Obesity and overweight. 2018. https://www. who.int/news-room/fact-sheets/detail/obesity-and-overweight.

2. Bondia-Pons I, Ryan L, Martinez JA. Oxidative stress and inflammation interactions in human obesity. J Physiol Biochem. 2012;68(4):701-11.

3. Setayesh T, Nersesyan A, Mišík M, Ferk F, Langie S, Andrade VM, Haslberger A, Knasmüller S. Impact of obesity and overweight on DNA stability: few facts and many hypotheses. Mutat Res. 2018;777:64-91.

4. Chen S, Yeh F, Lin J, Matsuguchi T, Blackburn E, Lee ET, Howard BV, Zhao J. Short leukocyte telomere length is associated with obesity in American Indians: the strong heart family study. Aging (Albany NY). 2014;6(5):380-9.

5. Mundstock E, Sarria EE, Zatti H, Mattos Louzada F, Kich Grun L, Herbert Jones M, Guma FT, Mazzola J, Epifanio M, Stein RT, Barbé-Tuana FM, Mattiello R. Effect of obesity on telomere length: Systematic review and meta-analysis. Obesity. 2015;23(11):2165-74.

6. Buxton $J$, Walters RG, Visvikis-Siest S, Meyre D, Froguel P, Blakemore Al. Childhood obesity is associated with shorter leukocyte telomere length. J Clin Endocrinol Metab. 2011:96(5):1500-5.

7. Clemente DBP, Maitre L, Bustamante M, Chatzi L, Roumeliotaki T, Fossati S, Grazuleviciene R, Gützkow KB, Lepeule J, Martens DS, McEachan RRC, Meltzer HM, Petraviciene I, Slama R, Tamayo-Uria I, Urquiza J, Vafeiadi M, Wright J, Nawrot TS, Vrijheid M. Obesity is associated with shorter telomeres in 8 year-old children. Sci Rep. 2019;9(1):18739.

8. Al-Attas OS, Al-Daghri N, Bamakhramah A, Shaun Sabico S, McTernan P, Huang $\Pi$. Telomere length in relation to insulin resistance, inflammation and obesity among Arab youth. Acta Paediatr. 2010;99(6):896-9.

9. Kjaer TW, Faurholt-Jepsen D, Mehta KM, Christensen VB, Epel E, Lin J, Blackburn E, Wojcicki JM. Shorter preschool, leukocyte telomere length is associated with obesity at age 9 in Latino children. Clin Obes. 2018; 8(2):88-94.

10. Zannolli R, Mohn A, Buoni S, Pietrobelli A, Messina M, Chiarelli F, Miracco C. Telomere length and obesity. Acta Paediatr. 2008;97(7):952-4.

11. Moyzis RK, Buckingham JM, Cram LS, Dani M, Deaven LL, Jones MD, Meyne J, Ratliff RL, Wu JR. A highly conserved repetitive DNA sequence, (TTAGGG) $n$, present at the telomeres of human chromosomes. Proc Natl Acad Sci U S A. 1988;85:6622-6.

12. Blackburn EH, Epel ES, Lin J. Human telomere biology: a contributory and interactive factor in aging, disease risks, and protection. Science. 2015; 350(6265):1193-8.

13. Arnoult N, Karlseder J. Complex interactions between the DNA-damage response and mammalian telomeres. Nat Struct Mol Biol. 2015;22(11): 859-66.

14. Barrett $J H$, lles MM, Dunning AM, Pooley KA. Telomere length and common disease: study design and analytical challenges. Hum Genet. 2015;134(7): 679-89. 
15. Wang Y, Feigon J. Structural biology of telomerase and its interaction at telomeres. Curr Opin Struct Biol. 2017;47:77-87.

16. Ozturk S. Telomerase activity and telomere length in male germ cells. Biol Reprod. 2015;92(2):53.

17. Brazvan B, Ebrahimi-Kalan A, Velaei K, Mehdipour A, Aliyari Serej Z, Ebrahimi A, Ghorbani M, Cheraghi O, Nozad CH. Telomerase activity and telomere on stem progeny senescence. Biomed Pharmacother. 2018;102:9-17.

18. Wojcicki JM, Shiboski S, Heyman MB, Elwan D, Lin J, Blackburn E, Epel E. Telomere length change plateaus at 4 years of age in Latino children: associations with baseline length and maternal change. Mol Gen Genomics. 2016;291(3):1379-89.

19. Gaspar TB, Sá A, Lopes JM, Sobrinho-Simões M, Soares P, Vinagre J. Telomere Maintenance Mechanisms in Cancer. Genes. 2018:9(5):241.

20. Lee DD, Leão R, Komosa M, Gallo M, Zhang CH, Lipman T, Remke M, Heidari A, Nunes NM, Apolónio JD, Price AJ, De Mello RA, Dias JS, Huntsman D, Hermanns T, Wild PJ, Vanner R, Zadeh G, Karamchandani J, Das S, Taylor MD, Hawkins CE, Wasserman JD, Figueiredo A, Hamilton RJ, Minden MD, Wani K, Diplas B, Yan H, Aldape K, Akbari MR, Danesh A, Pugh TJ, Dirks PB, Castelo-Branco P, Tabori U. DNA hypermethylation within TERT promoter upregulates TERT expression in cancer. J Clin Invest. 2019;129(4):1801.

21. Allegra A, Innao V, Penna G, Gerace D, Allegra AG, Musolino C. Telomerase and telomere biology in hematological diseases: a new therapeutic target. Leuk Res. 2017:56:60-74

22. Armanios M, Blackburn EH. The telomere syndromes. Nat Rev Genet. 2012; 13(10):693-704.

23. Srinivas N, Rachakonda S, Kumar R. Telomeres and telomere length: a general overview. Cancers. 2020;12(3):558.

24. Balan E, Decottignies A, Deldicque L. Physical activity and nutrition: two promising strategies for telomere maintenance? Nutrients. 2018;10(12):1942.

25. Mazidi M, Kengne AP, Banach M. Mineral and vitamin consumption and telomere length among adults in the United States. Pol Arch Intern Med. 2017;127(2):87-90

26. Zhu H, Guo D, Li K, Pedersen-White J, Stallmann-Jorgensen IS, Huang Y, Parikh S, Liu K, Dong Y. Increased telomerase activity and vitamin D supplementation in overweight African Americans. Int J Obes. 2012;36(6): 805-9.

27. Simopoulos AP. The importance of the omega-6/omega-3 fatty acid ratio in cardiovascular disease and other chronic diseases. Exp Biol Med. 2008;233: 674-88.

28. Ailhaud G, Massiera F, Weill P, Legrand P, Alessandri JM, Guesnet $P$. Temporal changes in dietary fats: role of $n-6$ polyunsaturated fatty acids in excessive adipose tissue development and relationship to obesity. Prog Lipid Res. 2006:45:203-36.

29. Albracht-Schulte K, Kalupahana NS, Ramalingam L, Wang S, Rahman SM, Robert-McComb J, Moustaid-Moussa N. Omega-3 fatty acids in obesity and metabolic syndrome: a mechanistic update. J Nutr Biochem. 2018;58:1-16.

30. Fan C, Zirpoli H, Qi K. N-3 fatty acids modulate adipose tissue inflammation and oxidative stress. Curr Opin Clin Nutr Metab Care. 2013;16(2):124-32.

31. Kulkarni A, Dangat K, Kale A, Sable P, Chavan-Gautam P, Joshi S. Effects of altered maternal folic acid, vitamin B12 and docosahexaenoic acid on placental global DNA methylation patterns in Wistar rats. PLoS One. 2011; 6(3):e17706

32. Shen W, Wang C, Xia L, Fan C, Dong H, Deckelbaum RJ, Qi K. Epigenetic modification of the leptin promoter in diet-induced obese mice and the effects of N-3 polyunsaturated fatty acids. Sci Rep. 2014;4:5282.

33. World Health Organization The WHO Child Growth Standards [EB/OL] Available online: http://www.who.int/childgrowth/standards/en/. Accessed 1 July 2016

34. Cawthon RM. Telomere measurement by quantitative PCR. Nucleic Acids Res. 2002;30(10):e47.

35. Lewin J, Schmitt AO, Adorján P, Hildmann T, Piepenbrock C. Quantitative DNA methylation analysis based on four-dye trace data from direct sequencing of PCR amplificates. Bioinformatics. 2004;20(17):3005-12.

36. Lepage G, Roy CC. Direct transesterification of all classes of lipids in a onestep reaction. J Lipid Res. 1986;27:114-20.

37. Rodríguez-Palmero M, Lopez-Sabater MC, Castellote-Bargallo Al, De la TorreBoronat MC, Rivero-Urgell M. Comparison of two methods for the determination of fatty acid profiles in plasma and enythrocytes. J Chromatogr A. 1997;778(1-2):435-9.

38. Tian C, Fan C, Liu X, Xu F, Qi K. Brain histological changes in young mice submitted to diets with different ratios of $n-6 / n-3$ polyunsaturated fatty acids during maternal pregnancy and lactation. Clin Nutr. 2011;30(5):659-67.
39. Brouilette SW, Moore JS, McMahon AD, Thompson JR, Ford I, Shepherd J, Packard CJ, Samani NJ, West of Scotland Coronary Prevention Study Group. Telomere length, risk of coronary heart disease, and statin treatment in the west of Scotland primary prevention study: a nested case-control study. Lancet. 2007;369(9556):107-14

40. Ping F, Li ZY, Lv K, Zhou MC, Dong YX, Sun Q, Li YX. Deoxyribonucleic acid telomere length shortening can predict the incidence of non-alcoholic fatty liver disease in patients with type 2 diabetes mellitus. J Diabet Invest. 2017; 8(2):174-80.

41. Zhao J, Zhu Y, Lin J, Matsuguchi T, Blackburn E, Zhang Y, Cole SA, Best LG, Lee ET, Howard BV. Short leukocyte telomere length predicts risk of diabetes in american indians: the strong heart family study. Diabetes. 2014; 63(1):354-62.

42. Shin YA. How does obesity and physical activity affect aging?: focused on telomere as a biomarker of aging. J Obes Metab Syndr. 2019;28(2):92-104

43. Feng $\mathrm{S}$, Jacobsen SE, Reik W. Epigenetic reprogramming in plant and animal development. Science. 2010;330(6004):622-7.

44. Gabory A, Attig L, Junien C. Developmental programming and epigenetics. Am J Clin Nutr. 2011;94(6 Suppl):1943S-52S.

45. Esopi D, Graham MK, Brosnan-Cashman JA, Meyers J, Vaghasia A, Gupta A Kumar B, Haffner MC, Heaphy CM, De Marzo AM, Meeker AK, Nelson WG, Wheelan SJ, Yegnasubramanian S. Pervasive promoter hypermethylation of silenced TERT alleles in human cancers. Cell Oncol. 2020. https://doi.org/10. 1007/s13402-020-00531-7.

46. Lee DD, Komosa M, Nunes NM, Tabori U. DNA methylation of the TERT promoter and its impact on human cancer. Curr Opin Genet Dev. 2020;60: $17-24$.

47. Barthel FP, Wei W, Tang M, Martinez-Ledesma E, Hu X, Amin SB, Akdemir KC, Seth S, Song X, Wang Q, Lichtenberg T, Hu J, Zhang J, Zheng S, Verhaak RG. Systematic analysis of telomere length and somatic alterations in 31 cancer types. Nat Genet. 2017:49(3):349-57.

48. Galiè S, Canudas S, Muralidharan J, García-Gavilán J, Bulló M, Salas-Salvadó J. Impact of nutrition on telomere health: systematic review of observational cohort studies and randomized clinical trials. Adv Nutr. 2020;11(3):576-601.

49. Cassidy A, De Vivo I, Liu Y, Han J, Prescott J, Hunter DJ, Rimm EB. Associations between diet, lifestyle factors, and telomere length in women. Am J Clin Nutr. 2010:91:1273-80.

50. Tucker LA. Dietary fiber and telomere length in 5674 U.S. adults: an NHANES study of biological aging. Nutrients. 2018;10(4):400.

51. Farzaneh-Far R, Lin J, Epel ES, Harris WS, Blackburn EH, Whooley MA Association of marine omega-3 fatty acid levels with telomeric aging in patients with coronary heart disease. JAMA. 2010;303(3):250-7.

52. Kiecolt-Glaser JK, Epel ES, Belury MA, Andridge R, Lin J, Glaser R, Malarkey WB, Hwang BS, Blackburn E. Omega-3 fatty acids, oxidative stress, and leukocyte telomere length: a randomized controlled trial. Brain Behav Immun. 2013;28:16-24

53. O'Callaghan N, Parletta N, Milte CM, Benassi-Evans B, Fenech M, Howe PR. Telomere shortening in elderly individuals with mild cognitive impairment may be attenuated with $\omega-3$ fatty acid supplementation: a randomized controlled pilot study. Nutrition. 2014;30(4):489-91.

54. Zhao Y, Wang B, Wang G, Huang L, Yin T, Li X, Liu X, Wang Q, Jing J, Yang $J$, Zhang $Y$. Functional interaction between plasma phospholipid fatty acids and insulin resistance in leucocyte telomere length maintenance. Lipids Health Dis. 2020;19(1):11.

55. Amatruda M, Ippolito G, Vizzuso S, Vizzari G, Banderali G, Verduci E. Epigenetic effects of $n-3$ LCPUFAs: a role in pediatric metabolic syndrome. Int J Mol Sci. 2019;20(9):2118.

56. Song Y, You NC, Song Y, Kang MK, Hou L, Wallace R, Eaton CB, Tinker LF, Liu S. Intake of small-to-medium-chain saturated fatty acids is associated with peripheral leukocyte telomere length in postmenopausal women. J Nutr. 2013;143(6):907-14.

57. Tiainen AM, Männistö S, Blomstedt PA, Moltchanova E, Perälä MM, Kaartinen NE, Kajantie E, Kananen L, Hovatta I, Eriksson JG. Leukocyte telomere length and its relation to food and nutrient intake in an elderly population. Eur J Clin Nutr. 2012;66(12):1290-4

58. Rolland-Cachera MF, Akrout M, Péneau S. Nutrient intakes in early life and risk of obesity. Int J Environ Res Public Health. 2016;13(6):564.

\section{Publisher's Note}

Springer Nature remains neutral with regard to jurisdictional claims in published maps and institutional affiliations. 